ISSN 1112-9867

\title{
EFFECTS OF SILICA COMPOSITION ON GAS PERMEABILITY OF ENR/PVC MEMBRANE
}

\author{
N. Jon ${ }^{1, *}$, N. A. Abdullah ${ }^{1}$ and R. Othaman ${ }^{2}$ \\ ${ }^{1}$ Faculty of Applied Sciences, UniversitiTeknologi MARA, 35400 Tapah, Perak, Malaysia \\ ${ }^{2}$ School of Chemical Sciences and Food Technology, Faculty of Science and Technology, \\ UniversitiKebangsaan Malaysia, 43600 Bangi, Selangor, Malaysia
}

Published online: 10 November 2017

\begin{abstract}
This paper studied the potential of a hybrid organic-inorganic membrane, ENR/PVC/SiO ${ }_{2}$ membrane for separation purposes. The $\mathrm{ENR} / \mathrm{PVC} / \mathrm{SiO}_{2}$ membranes were prepared using spontaneous solvent exchange and evaporation techniques. The amount of $\mathrm{SiO}_{2}$ added was varied at 1, 3, 5 and $8 \mathrm{wt} \%$. The SEM micrographs showed that pores were developed upon addition of $\mathrm{SiO}_{2}$. The tensile strength and modulus were also enhanced with increasing amount of $\mathrm{SiO}_{2}$ up to $5 \mathrm{wt} \%$. At higher $\mathrm{SiO}_{2}$ loadings, the mechanical strength of the membrane decreased due to the agglomeration of $\mathrm{SiO}_{2}$ particles. Gas permeation test was done on $\mathrm{ENR} / \mathrm{PVC} / \mathrm{SiO}_{2}$ membranes using $\mathrm{NO}_{2}$ gas and $\mathrm{CO}_{2}$ gas. The permeability of both gasses increased with the amount of $\mathrm{SiO}_{2}$ added to the membrane, which attributed to the increase in nanopores. The membranes with $\mathrm{SiO}_{2}$ had a higher permeability to $\mathrm{CO}_{2}$ than $\mathrm{NO}_{2}$.
\end{abstract} Keywords: epoxidised natural rubber; polyvinyl chloride; membrane; silica; gas separation.

Author Correspondence, e-mail: nazwa0554@perak.uitm.edu.my doi: http://dx.doi.org/10.4314/jfas.v9i6s.48 


\section{INTRODUCTION}

Hybrid organic-inorganic materials have been developed for various applications such as catalysts, electronics, optics, coatings and membranes. These materials combine the flexibility and ductility of organic polymers with the good mechanical and thermal properties of inorganic materials [1]. The development of new organic-inorganic membranes for ultrafiltration, nanofiltration, reverse osmosis, pervaporation and gas separation offers great improvements in separation process. The addition of inorganic particles such as silica $\left(\mathrm{SiO}_{2}\right)$, titania $\left(\mathrm{TiO}_{2}\right)$, zirconia $\left(\mathrm{ZrO}_{2}\right)$ and zeolite into the polymer matrix help to improve the physical and separation properties of a membrane.

The application of hybrid organic-inorganic membrane particularly in gas separation offers new or improved properties compared with the single organic or inorganic materials [2]. The rigidity and thermal stability of inorganic material and flexibility, ductility and processability of the organic polymer combine to produce enhanced properties in the new membranes [3]. Numerous studies on the fabrication of hybrid organic-inorganic for gas separation have been explored. For instance, combinations such as, polyimide/ $/ \mathrm{TiO}_{2}$ [4], polyimide $/ \mathrm{SiO}_{2}$ [5], ethylene vinyl acetate/ $\mathrm{SiO}_{2}[1]$, polysulfone/ $\mathrm{SiO}_{2}[6]$ and $\mathrm{MgO}$ incorporated $\mathrm{ENR} / \mathrm{PVC} / \mathrm{MgO}$ membranes [7] were shown to have improved efficiency in gas permeation studies. The addition of inorganic particles in the polymer matrix can affect gas separation properties by increasing the free volume between polymer chains that promotes gas diffusion. Besides that, the functional groups on the surface of inorganic particles can interact with any interacting gasses such as $\mathrm{CO}_{2}$, thus improving the solubility in the membrane [1].

Polymer blends have generated a lot of interest due to the individual polymeric properties can be modified to obtain the desired new properties. The compatibility of ENR and PVC will produce a miscible blend at any compositional ratio [8]. In fact, the improvement in tensile properties of ENR/PVC has been reported in literatures [8-9]. PVC is an outstanding material due to its stiffness, low cost, excellent physical and chemical properties, acids, alkaline and solvent resistance as well as superior mechanical properties. ENR is a good elastomer because of its flexibility and stability. ENR was blended in dominant to produce a flexible and mechanically tough matrix that is suitable for fabrication of self-supporting membrane. The addition of inorganic particles will help in creating pores of the membrane. In [10] proposed a 
technique of incorporation of inorganic nanoparticle (silica) in the cellulose acetate membranes. Some of the silica nanoparticles were instantly diffused into the coagulation bath during the phase inversion process and the spaces left turned into pores by the silica on the membrane.

The properties and characterization $\mathrm{ENR} / \mathrm{PVC} / \mathrm{SiO}_{2}$ membrane were investigated. The $\mathrm{ENR} / \mathrm{PVC} / \mathrm{SiO}_{2}$ membranes were prepared by adding fumed silica powder in various compositions into the ENR/PVC blend in the ratio of $60: 40 \mathrm{wt} \%$. The membrane was prepared by simultaneous solvent exchange and evaporation technique [11]. The objective of this study was to determine the effect of silica incorporation into ENR/PVC membrane on the gas permeability. The membranes were characterized on the morphology, mechanical stabilities and gas permeation.

\section{EXPERIMENTAL}

\subsection{Materials}

Epoxidised Natural Rubber (ENR-50) and Polyvinyl chloride (PVC) were purchased from Malaysia Rubber Board and Sigma-Aldrich respectively. Tetrahydrofuran (THF), toluene and fumed silica powder $(0.007 \mu \mathrm{m})$ were purchased from Systerm.

\subsection{Preparation of Membranes}

ENR/PVC matrix $(60 / 40 \mathrm{wt} \%)$ was prepared by melt-blending using an internal mixer (BrabenderPlasticoder-PL 2000) at $160{ }^{\circ} \mathrm{C}$ and a mixing rate of $50 \mathrm{rpm}$ for 13 minutes. The matrix was swelled and dissolved in a solvent, a mixture of THF:toluene, 97.5:2.5 (v/v) at the matrix to the solvent ratio $1: 8(\mathrm{w} / \mathrm{v})$ for 24 hours. The ENR/PVC solution wasthen continuously stirred for another 24 hours for homogenization. Fumed nanosilica powder by the composition of $1,3,5$ and $8 \mathrm{wt} \%$ was added into the ENR/PVC solution and stirred for another 24 hours. The membrane was prepared by a spontaneous spreading of the polymer solution on the surface of deionized water by using a syringe. $4 \mathrm{ml}$ of the polymer solution formed into a thin film of about $50 \mathrm{~cm}^{2}$ due to surface tension. The syringe was held sufficiently close to the water surface to minimize disturbances (e.g.: air, dust, vibration). The phase inversion process occurred instantaneously for 30 minutes until the film solidified. The prepared membranes were collected, rinsed and dried at room temperature. 


\subsection{Characterization}

The surface morphology of the membranes were observed using a scanning electron microscope (LEO 1450VP). Tensile properties of the membranes were determined using Universal Testing Machine (Instron 5566) at a cross-head speed of $50 \mathrm{~mm} / \mathrm{min}$. Samples of dumbbell shaped were cut out for each membrane according to the ASTMD 412 standard.

\subsection{Gas Permeation Test}

The permeability of carbon dioxide $\left(\mathrm{CO}_{2}\right)$ gas and nitrogen $\left(\mathrm{N}_{2}\right)$ gas were measured using constant pressure/variable volume technique at 2, 4, 5 and 6 psi pressures at room temperature [1]. The gas permeability of membranes was determined using the following equation:

$$
\mathrm{P}=\frac{\mathrm{q} l}{\mathrm{~A}\left(\mathrm{p}_{1}-\mathrm{p}_{2}\right)}
$$

where $\mathrm{P}$ is the permeability expressed in $\mathrm{cm}^{2} / \mathrm{s} \cdot \mathrm{cmHg}$, $\mathrm{q}$ is the flow rate of the permeate gas passing through membrane $\left(\mathrm{cm}^{3} / \mathrm{s}\right), 1$ is the membrane thickness $(\mathrm{cm}), \mathrm{p}_{1}$ and $\mathrm{p}_{2}$ are the pressures of feed and permeate sides $(\mathrm{cmHg})$ respectively and Ais the effective area of the membrane $\left(\mathrm{cm}^{2}\right)$.

The selectivity, $\alpha$ of the membranes was calculated from pure gas experiments:

$$
\alpha=\frac{\mathrm{P}_{\mathrm{CO}_{2}}}{\mathrm{P}_{\mathrm{N}_{2}}}
$$

\section{RESULTS AND DISCUSSION}

\subsection{Morphology Studies}

Fig. 1 shows the SEM surface morphologies of ENR/PVC and ENR/PVC with the addition of $1 \mathrm{wt} \%, 3 \mathrm{wt} \%, 5 \mathrm{wt} \%$ and $8 \mathrm{wt} \% \mathrm{SiO}_{2}$. There are pores developed in the ENR/PVC/SiO 2 membranes (Fig. 1d-1e) in contrast to the control ENR/PVC membrane (Fig. 1a). The surface morphology of $\mathrm{ENR} / \mathrm{PVC} / 1 \% \mathrm{SiO}_{2}$ is quite similar to the control ENR/PVC membrane, which may be due to the low silica loading. However, as the silica loading increases, the number of pores developed in the membrane also increases. The development of pores in the membrane is also due to the affinity of silica towards non-solvent (water) [10]. In other words, when the polymer solution is dropped onto the water surface, some of the silica diffuses into the water until the membrane is cured. The distribution of pores in the membrane with silica 
composition of below $5 \mathrm{wt} \%$ is homogenous. However, in $\mathrm{ENR} / \mathrm{PVC} / 8 \% \mathrm{SiO}_{2}$, the size of pores is larger compared to the other membranes. This is probably due to the agglomeration of silica during membrane solution mixing. This is supported by the amount of silica that remained in the membrane that is lower than the initial amount of silica added. In [6] also made a similar observation whereby nanoparticles appear to form agglomerates in the polymer matrix at higher silica content. The agglomerated silica disrupted the polymer chain segments and thus increased the free volume between the polymer chains. The agglomeration of silica can be reduced by optimizing the stirring rate, time and etc.

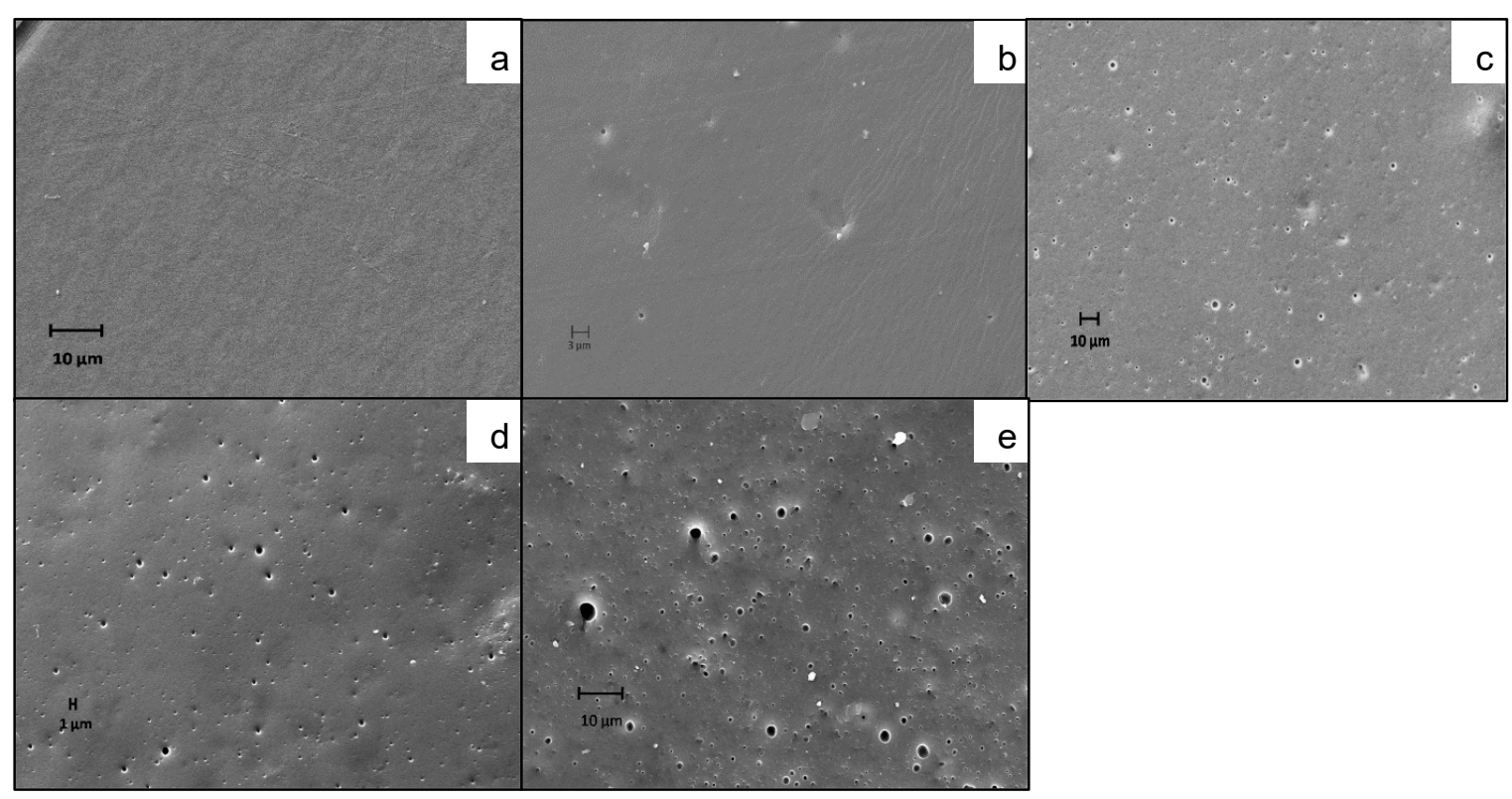

Fig.1. Surface morphology of (a) ENR/PVC (b) ENR/PVC/1\% $\mathrm{SiO}_{2}$ (c) ENR/PVC/3\% $\mathrm{SiO}_{2}$ (d) $\mathrm{ENR} / \mathrm{PVC} / 5 \% \mathrm{SiO}_{2}(\mathrm{e}) \mathrm{ENR} / \mathrm{PVC} / 8 \% \mathrm{SiO}_{2}$ at $1000 \times$ magnification

\subsection{Tensile Properties}

The results of tensile properties of each membrane are shown in Fig. 2. Tensile strength and modulus of the ENR/PVC increase with silica content and maximum of tensile strength 12.1 $\mathrm{MPa}$ and modulus $9.1 \mathrm{MPa}$ at the $5 \mathrm{wt} \% \mathrm{SiO}_{2}$ addition was recorded. In [12] reported similar results reinforced cellulose acetate membrane $\mathrm{SiO}_{2}$ reinforced membrane in terms of tensile stress and elongation at break for cellulose acetate membrane with an addition of $\mathrm{SiO}_{2}$.

The improvement of mechanical properties is rationalized as due to the good interaction between silica and the polymer matrix. According to [12], $\mathrm{SiO}_{2}$ particles could act as points of crosslinking in the polymer network chains and thus increases the polymer chain rigidity. 
More energy is needed to break the bonds between the filler and the polymer matrix, resulting in the improved mechanical strength of the membranes.

Further increase of $\mathrm{SiO}_{2}$ content at $8 \mathrm{wt} \%$ causes the tensile strength to decrease to $9.3 \mathrm{MPa}$ and modulus $8.8 \mathrm{MPa}$. At higher $\mathrm{SiO}_{2}$ loadings, the silica increases the rigidity of the membrane arising the formation of silica network structure which consequently lowers the tensile strength and modulus of the membranes. According to [13], an excessive filler loading will cause the filler particles not to disperse uniformly in the polymer matrix. As a result, the elasticity and the mechanical stability of the membranes will be reduced. The increase in the pore size (refer to Fig. 1) was also one of the contributing factors that lowers the mechanical properties of the $\mathrm{ENR} / \mathrm{PVC} / 8 \% \mathrm{SiO}_{2}$ membrane.

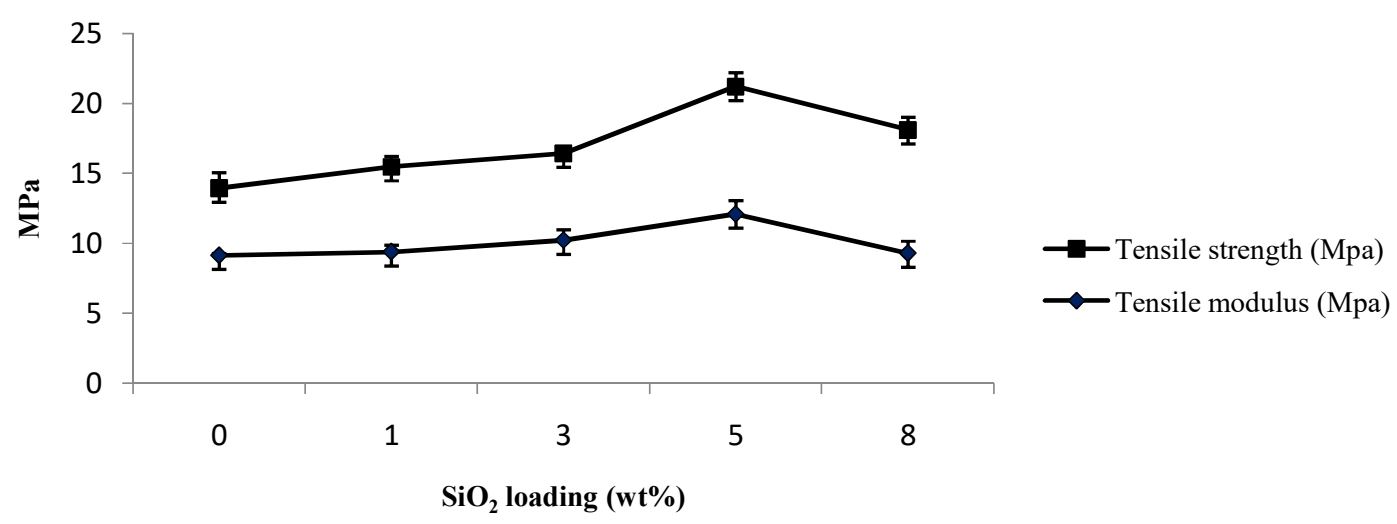

Fig.2. Tensile strength and modulus of ENR/PVC and ENR/PVC/SiO 2

\subsection{Gas Permeation Studies}

The variation of permeation of $\mathrm{N}_{2}$ and $\mathrm{CO}_{2}$ through ENR/PVC and ENR/PVC/SiO membranes under pressures of 2, 4, 5 and 6 psi are shown in Fig. 3. The permeability of both gases in the membrane increases with increasing silica loading. In [14] also found similar results that $\mathrm{ENR} / \mathrm{PVC} / \mathrm{SiO}_{2}$ membranes are more permeable compared to $\mathrm{ENR} / \mathrm{PVC} / \mathrm{MgO}$ with increasing filler loading. The addition of silica particles disrupts the polymer chain, thus increase the free volume between the polymer chains. Due to the fact that the kinetic diameter of $\mathrm{CO}_{2}(3.3 \AA)$ is also smaller than $\mathrm{N}_{2}(3.64 \AA)$, smaller gas molecules will diffuse at a much faster rate than larger gas molecules [15]. There is also the possibility of the membrane to separate other gases such as $\mathrm{H}_{2}, \mathrm{CO}, \mathrm{CH}_{2}$ and $\mathrm{N}_{2}$.

The permeability of $\mathrm{CO}_{2}$ gas is relatively greater than that of $\mathrm{N}_{2}$ gas for all membranes. $\mathrm{N}_{2}$ 
gas is considered a non-interacting gas, whereas $\mathrm{CO}_{2}$ gas interacts with the membrane. This is due to the high interaction possible between $\mathrm{CO}_{2}$ and $\mathrm{OH}$ group on the silica particles [16]. According to the solution-diffusion mechanism, the permeability of gasses through the polymer membranes is based on the combination of solution and diffusion process [17]. The incorporation of silica in the polymer matrix enhances the solubility and causes diffusivity of $\mathrm{CO}_{2}$ to increase [18].

Table 1 shows the selectivity $\mathrm{CO}_{2} / \mathrm{N}_{2}$ of ENR/PVC membranes of various silica loadings. The selectivity of the membranes does not change significantly with the increase or decrease of experimental pressure. However, the selectivity $\mathrm{CO}_{2} / \mathrm{N}_{2}$ increases upon increasing silica loadings. This is most likely due to the solubility of the gases. Available sorption sites and pathways at the interfaces and in the silica domains for the condensable gas $\left(\mathrm{CO}_{2}\right)$ had increased with increasing silica contents.
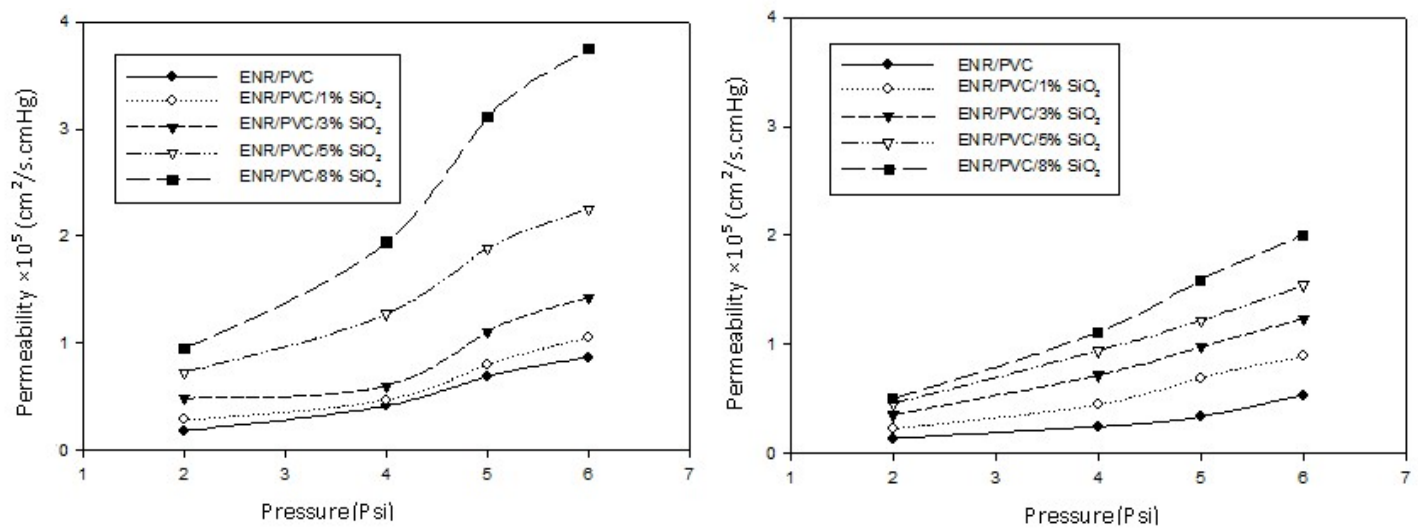

Fig.3. Gas permeation through ENR/PVC and $\mathrm{ENR} / \mathrm{PVC} / \mathrm{SiO}_{2}$ a) $\mathrm{N}_{2}$ gas b) $\mathrm{CO}_{2}$ gas

Table 1.Selectivity coefficients of ENR/PVC with various $\mathrm{SiO}_{2}$ loadings

\begin{tabular}{ccccc}
\hline Membrane & \multicolumn{4}{c}{ Pressure (psi) } \\
& $\mathbf{2}$ & $\mathbf{4}$ & $\mathbf{5}$ & $\mathbf{6}$ \\
\hline $\mathrm{ENR} / \mathrm{PVC}$ & 1.33 & 1.7 & 2.05 & 1.63 \\
$\mathrm{ENR} / \mathrm{PVC} / 1 \% \mathrm{SiO}_{2}$ & 1.25 & 1.05 & 1.15 & 1.18 \\
$\mathrm{ENR} / \mathrm{PVC} / 3 \% \mathrm{SiO}_{2}$ & 1.39 & 0.84 & 1.14 & 1.15 \\
$\mathrm{ENR} / \mathrm{PVC} / 5 \% \mathrm{SiO}_{2}$ & 1.60 & 1.35 & 1.54 & 1.46 \\
$\mathrm{ENR} / \mathrm{PVC} / 8 \% \mathrm{SiO}_{2}$ & 1.90 & 1.75 & 1.97 & 1.87 \\
\hline
\end{tabular}




\section{CONCLUSION}

The ENR/PVC membranes were successfully prepared using phase inversion via spontaneous solvent exchange and evaporation technique. The mechanical study verified that the mechanical stabilities of the membranes has improved with the addition of silica. The mechanical properties, tensile strength, and modulus, improved with increasing amount of silica up to $5 \mathrm{wt} \%$ loading indicating the reinforcement effect of silica added. The surface morphologies of the membranes showed that pores were developed in the addition of silica and the number of pores increased with the amount of silica. A significant increase in the permeability of both $\mathrm{CO}_{2}$ and $\mathrm{N}_{2}$ gases were observed upon increasing silica content. The selectivity $\mathrm{CO}_{2} / \mathrm{N}_{2}$ also increased upon increasing silica loadings. In addition to reinforcing effect, silica appeared to function as a pore former and gas permeability enhancement of the membrane.

\section{ACKNOWLEDGEMENTS}

Acknowledgments are dedicated to University Teknologi MARA (UiTM) Cawangan Perak, Research Management Institute (RMI) UiTM and UiTM Excellence Fund for the financial support.

\section{REFERENCES}

[1] Sadeghi M, Khanbabaei G, Dehaghani AH, Sadeghi M, Aravand MA, Akbarzade M, Khatti S. Gas permeation properties of ethylene vinyl acetate-silica nanocomposite membranes. Journal of Membrane Science, 2008, 322(2):423-428

[2] Guizard C, Bac A, Barboiu M, Hovnanian N. Hybrid organic-inorganic membranes with specific transport properties: Applications in separation and sensors technologies. Separation and Purification Technology, 2001, 25(1):167-180

[3] Zou H, Wu S, Shen J. Polymer/silica nanocomposites: preparation, characterization, properties, and applications. Chemical Reviews, 2008, 108(9):3893-3957

[4] Hu Q, Marand E, Dhingra S, Fritsch D, Wen J, Wilkes G. Poly (amide-imide)/TiO2 nano-composite gas separation membranes: Fabrication and characterization. Journal of Membrane Science, 1997, 135(1):65-79 
[5] Cornelius CJ, Marand E. Hybrid silica-polyimide composite membranes: Gas transport properties. Journal of Membrane Science, 2002, 202(1):97-118

[6] Ahn J, Chung WJ, Pinnau I, Guiver MD. Polysulfone/silica nanoparticle mixed-matrix membranes for gas separation. Journal of Membrane Science, 2008, 314(1):123-133

[7] Nor FM, Karim NH, Abdulla.h I, Othaman R. Permeability of carbon dioxide and nitrogen gases through $\mathrm{SiO}_{2}$ and $\mathrm{MgO}$ incorporated ENR/PVC membranes. Journal of Elastomers and Plastics, 2016, 48(6):483-498

[8] Ratnam CT, Zaman K. Stabilization of poly (vinyl chloride)/epoxidized natural rubber (PVC/ENR) blends. Polymer Degradation and Stability, 1999, 65(1):99-105

[9] Varughese KT, Nando GB, De PP, Sanyal SK. Miscible blends from rigid poly (vinyl chloride) and epoxidized natural rubber. Journal of Materials Science, 1988, 23(11):3903-3909

[10] Chen W, Su Y, Zhang L, Shi Q, Peng J, Jiang Z. In situ generated silica nanoparticles as pore-forming agent for enhanced permeability of cellulose acetate membranes. Journal of Membrane Science, 2010, 348(1):75-83

[11] Jon N, Samad NA, Abdullah NA, Abdullah I, Othaman R. Influence of silica addition on the properties of epoxidised natural rubber/polyvinyl chloride composite membrane. Journal of Applied Polymer Science, 2013, 129(5):2789-2795

[12] Yu LY, Xu ZL, Shen HM, Yang H. Preparation and characterization of PVDF-SiO 2 composite hollow fiber UF membrane by sol-gel method. Journal of Membrane Science, $2009,337(1): 257-265$

[13] Arthanareeswaran G, Devi TS, Raajenthiren M. Effect of silica particles on cellulose acetate blend ultrafiltration membranes: Part I. Separation and Purification Technology, 2008, 64(1):38-47

[14] Nor FM, Abdullah I, Othaman R. Gas permeability of ENR/PVC membrane with the addition of inorganic fillers. AIP Conference Proceedings, 2013, 1571(1):911-917

[15] Kentish SE, Scholes CA, Stevens GW. Carbon dioxide separation through polymeric membrane systems for flue gas applications. Recent Patents on Chemical Engineering, 2008, 1(1):52-66

[16] Wahab MF, Ismail AF, Shilton SJ. Studies on gas permeation performance of asymmetric 
polysulfone hollow fiber mixed matrix membranes using nanosized fumed silica as fillers. Separation and Purification Technology, 2012, 86:41-48

[17] Mulder J. Basic principles of membrane technology. Berlin: Springer Science and Business Media, 2012

[18] Cong H, Radosz M, Towler BF, Shen Y. Polymer-inorganic nanocomposite membranes for gas separation. Separation and Purification Technology, 2007, 55(3):281-291

\section{How to cite this article:}

Jon N, Abdullah N A, Othaman R. Effects of silica composition on gas permeability of enr/pvc membrane. J. Fundam. Appl. Sci., 2017, 9(6S), 632-641. 